\title{
Reduction of the Negative Impact on the Environment By Optimizing the Combustion Process in Diesel Engines
}

\section{Aleksandr Barinov}

Murmansk State Technical University

\section{Abstract}

The article considers the problem of the negative impact of the exhaust gases of diesel internal combustion engines on the environment and human health. The types of organization of the ignition process and the process of fuel combustion in a diesel engine are considered. The reasons for the occurrence of increased particulate matter in internal combustion engines in exhaust gases are also described. The main factors affecting the delay of ignition are given. The main stages of soot formation in diesel internal combustion engines are described. The influence of temperature distribution in the jets of injected fuel and the dependence of emissions on the coefficient of

Corresponding Author: Aleksandr Barinov

asbarinov2012@mail.ru

Received: 24 December 2019

Accepted: 9 January 2020

Published: 15 January 2020

Publishing services provided by Knowledge E

(c) Aleksandr Barinov. This article is distributed under the terms of the Creative Commons

Attribution License, which permits unrestricted use and redistribution provided that the original author and source are credited.

Selection and Peer-review under the responsibility of the BRDEM-2019 Conference Committee.

\section{G OPEN ACCESS}

\section{Introduction}

The exhaust gases of automotive internal combustion engines have a significant impact on the environment and human health. The issue of reducing particulate matter is particularly relevant in our time. The main harmful components of automobile exhaust gases include:

- carbon monoxide CO (strong toxic substance);

- hydrocarbons $\mathrm{CHx}$;

- nitrogen oxides NOx (toxic, together with hydrocarbons $\mathrm{CH}$ forms

photochemical smog);

- aldehydes (harmful effects on the nervous system and respiratory system);

- solid particles, PM (soot);

- sulfur oxides SOx;

- benzapyrene;

- lead salts (highly toxic substances) [2]. 
Among the named "harmful" components of the exhaust gases, PM 2.5 (BC, "black carbon") should be highlighted. Aircraft emissions are especially high for diesel engines where diffusion combustion takes place. However, almost the same combustion occurs in engines with spark ignition and direct fuel injection. The aircraft emission from such engines is poorly studied and, in our opinion, is an urgent problem that needs to be solved [2].

Methods of reducing atmospheric pollution with exhaust gases of internal combustion engines can be divided into two groups:

- methods for reducing emissions toxicity;

- methods for reducing emissions [3].

\section{Methods and Equipment}

The processes of diesel combustion in internal combustion engines were investigated. During the research, the stages of supplying diesel fuel to the combustion chamber, the formation of a fuel-air mixture and its further ignition were considered.

When organizing the ignition process in diesel internal combustion engines, different methods can be used, such as injection into separate combustion chambers or direct injection. Currently, the use of prechamber and vortex chamber mixture formation is not used so often. Now direct injection systems are used.

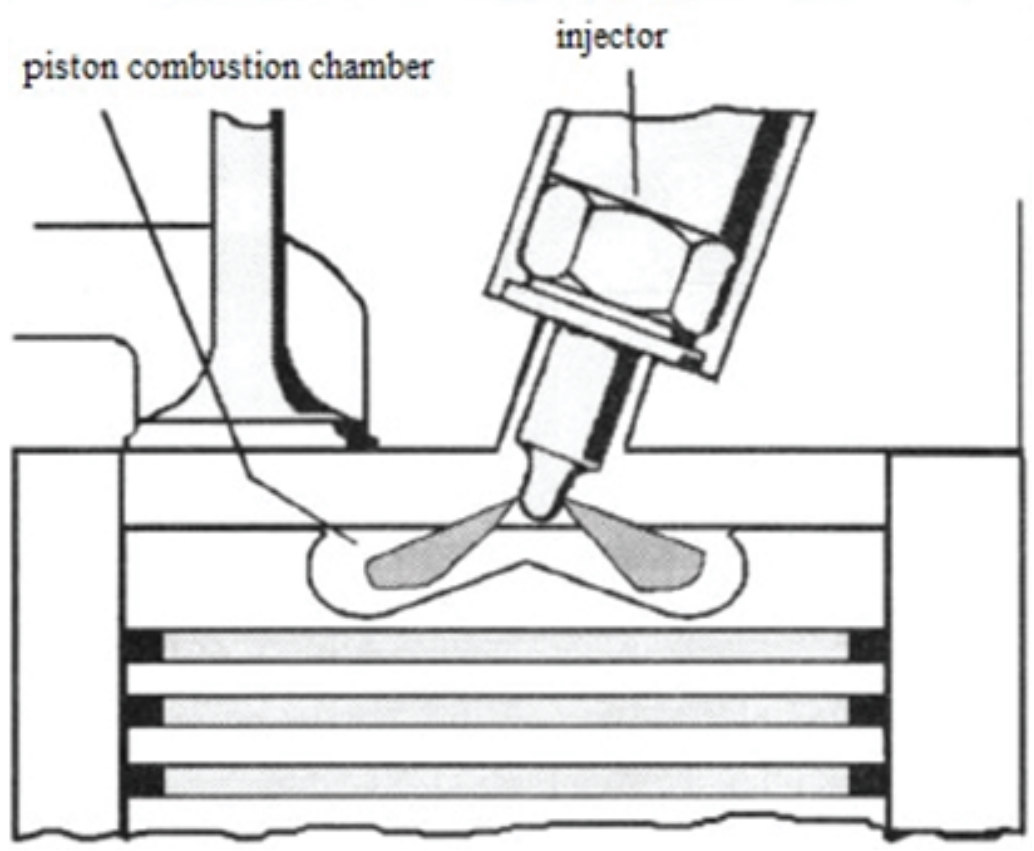

Figure 1: Direct injection. 
The main difference between diesel internal combustion engines of trucks and cars is the geometry of the combustion chamber and the types of nozzles used.

The main advantages of direct injection:

- the ability to reduce fuel consumption;

- higher thermal efficiency;

- less heat loss.

Disadvantages of direct injection:

- the vortex flow interferes with the cleaning of the combustion chamber;

- problems with a cold start;

- it is difficult to cool the combustion chamber.

The position and number of jets in the combustion chamber with direct injection affect:

- conditions of mixture formation;

- the process of ignition of the mixture;

- engine efficiency;

- pressure rise rate;

- engine power and torque;

- conditions for soot formation and particle ejection;

- use of air to burn fuel;

- fuel consumption.

\section{Results}

The formation of soot and particulate matter in the exhaust gases of diesel internal combustion engines occur under three basic conditions:

- injection of cold, liquid fuel into the combustion front;

- lack of oxygen and poor conditions for the formation of the mixture;

- drop in pressure or temperature in the combustion chamber and premature termination of combustion.

Ignition retardation is the time from the start of injection to the start of pressure rise above the compression pressure.

The combustion process and the composition of the exhaust gases is determined by the ignition delay process [13]. 
TABLE 1: Factors Affecting Ignition Delay.

\begin{tabular}{|c|c|c|}
\hline Influencing value & Influence at & $\begin{array}{l}\text { Requirements for optimal } \\
\text { ignition delay }\end{array}$ \\
\hline Compression ratio & $\begin{array}{l}\text { - Temperature difference } \\
\text { between air and fuel } \\
\text { - air pressure and heat transfer } \\
\text { coefficient } \\
\text { - oxygen concentration in the } \\
\text { combustion chamber }\end{array}$ & Big as possible \\
\hline Initial compression pressure & $\begin{array}{l}\text { - Total pressure in the engine } \\
\text { and heat transfer coefficient } \\
\text { - oxygen concentration in the } \\
\text { combustion chamber }\end{array}$ & Big \\
\hline Initial compression temperature & $\begin{array}{l}\text { Temperature difference } \\
\text { between air and fuel }\end{array}$ & Big \\
\hline Engine speed & $\begin{array}{l}\text { Time to transfer heat from air to } \\
\text { fuel }\end{array}$ & Small \\
\hline Engine load & $\begin{array}{l}\text { - Level of temperature and } \\
\text { pressure in the cylinder } \\
\text { - heat transfer coefficient }\end{array}$ & Big \\
\hline $\begin{array}{l}\text { The movement of air in the } \\
\text { combustion chamber }\end{array}$ & $\begin{array}{l}\text { - Heat transfer from air to fuel } \\
\text { - speed difference between air } \\
\text { and fuel }\end{array}$ & Very big \\
\hline Spray quality & $\begin{array}{l}\text { - Fuel droplet size } \\
\text { - the ratio of the surface area of } \\
\text { the droplets to their volume }\end{array}$ & Very big \\
\hline Fuel density & $\begin{array}{l}\text { The surface area of the fuel } \\
\text { droplets at constant weight }\end{array}$ & Small \\
\hline Specific heat of fuel & $\begin{array}{l}\text { The required amount of heat for } \\
\text { heating the fuel and the time for } \\
\text { delaying ignition }\end{array}$ & Small \\
\hline Flammability & $\begin{array}{l}\text { Decay processes of } \\
\text { hydrocarbon chains }\end{array}$ & Cetane number greater \\
\hline
\end{tabular}

The great importance in preparing fuel for which ignition is presented by the temperature distribution in the jets of injected fuel into the combustion chamber.

Figure 2 shows the temperature distribution in the injected jet when it comes in contact with hot air in the combustion chamber.

The light fuel components located on the periphery of the jet are crushed to even smaller droplets of fuel upon contact with air. The components of the fuel that come into contact with the hot air first boil and evaporate. In the core of the jet, the fuel remains cold, liquid and unprepared for a long time.

Accelerated soot formation is observed at temperatures in the combustion chamber above $2050 \mathrm{~K}$, and its maximum concentration at a temperature of about $2200 \mathrm{~K}$. At higher temperatures, the rate of soot oxidation begins to exceed the rate of soot formation and the amount of soot in the exhaust gases decreases.

The soot oxidation proceeds according to the following main reactions: 


$$
\begin{aligned}
& \mathrm{C}+\mathrm{O}_{2} \rightarrow \mathrm{CO}_{2} \\
& 2 \mathrm{C}+\mathrm{O}_{2} \rightarrow 2 \mathrm{CO} \\
& \mathrm{C}+\mathrm{CO}_{2} \rightarrow 2 \mathrm{CO} \\
& \mathrm{C}+\mathrm{H}_{2} \mathrm{O} \rightarrow \mathrm{CO}+\mathrm{H}_{2} \\
& \mathrm{C}+2 \mathrm{H}_{2} \mathrm{O} \rightarrow \mathrm{CO}_{2}+2 \mathrm{H}_{2} \\
& \mathrm{C}+2 \mathrm{H}_{2} \rightarrow \mathrm{CH}_{4}
\end{aligned}
$$

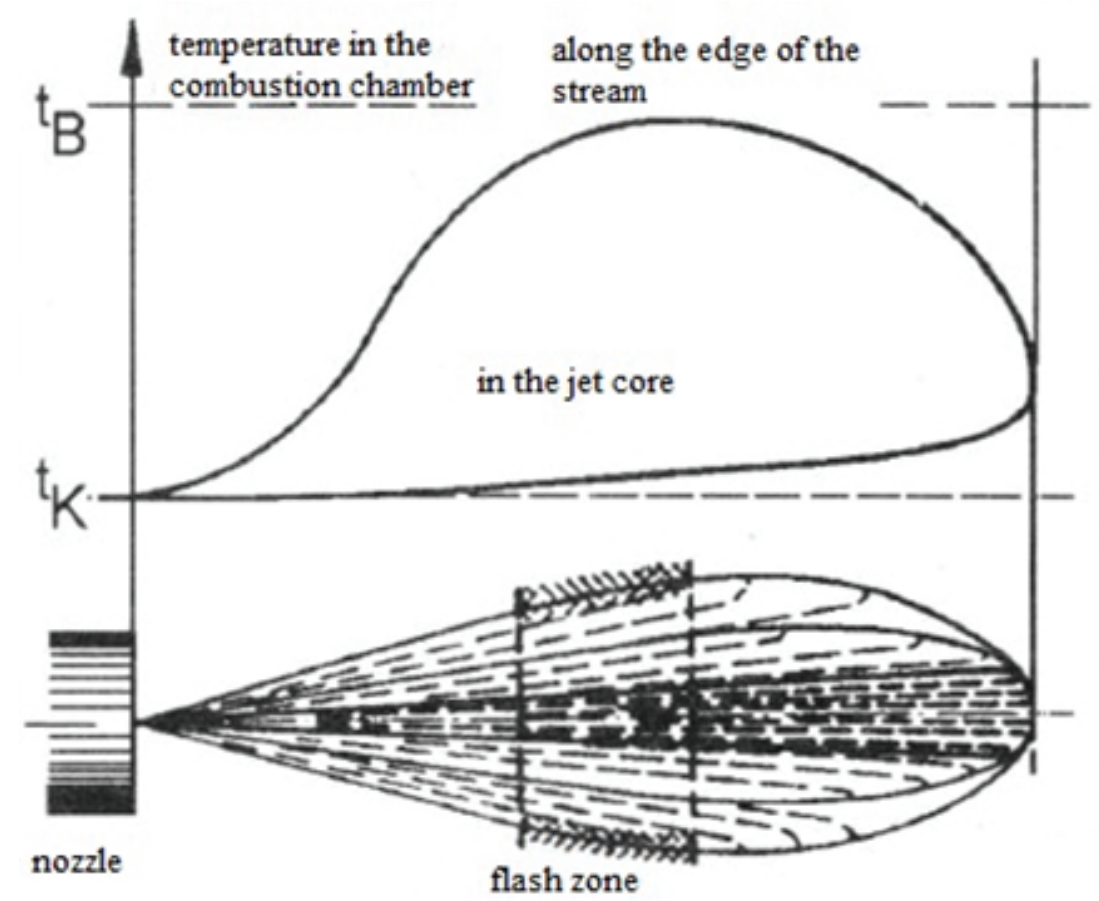

Figure 2: Temperature distribution: $\mathrm{t}_{K}$-- temperature in the core of the fuel jet, $\mathrm{t}_{B}$-- temperature along the edge of the fuel stream

At the same time, a significant part of the soot burns out in the combustion chamber at the expansion stroke and in the exhaust system of the diesel engine.

Primary soot particles have a diameter of about $0.02-0.17$ microns, and soot in the exhaust gases of diesel engines can be in the form of formations, most of which have a size of 0.5 microns. With an arithmetic average diameter of about 0.3 microns, soot particles have a very developed surface equal to about $90 \mathrm{~m}^{2}$ per $1 \mathrm{~g}$ of carbon black [12].

When soot is inhaled, its particles have a harmful effect on the respiratory organs of a person. They reach the alveoli of the lungs or are deposited in the sinuses, trachea or bronchi. Moreover, large particles of soot (2-10 microns or more) are easily excreted from the body, and small ones (0.5-2 microns) are retained in the lungs, causing chronic diseases. But the main toxic properties of soot are not caused by carbon, but by the presence of carcinogenic polycyclic aromatic hydrocarbons in it, including the most 


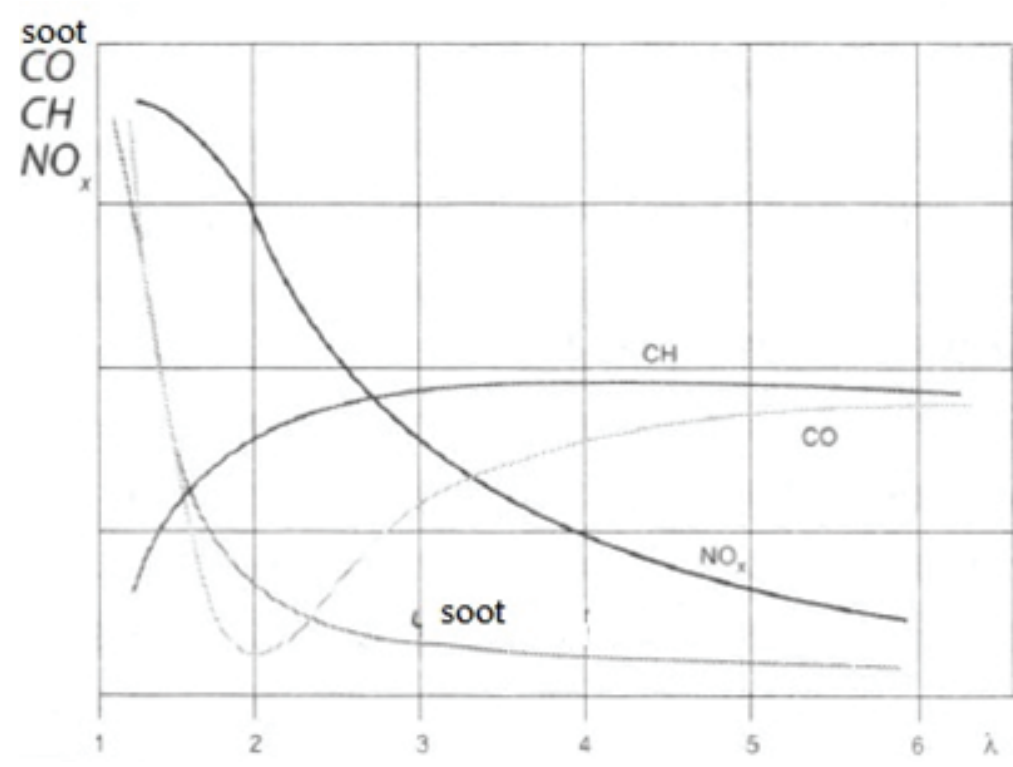

Figure 3: Coefficient of excess air and emissions of harmful substances from a diesel engine: CO - carbon monoxide; $\mathrm{CH}$ are hydrocarbons; $\mathrm{NO}_{x}$ - nitrogen oxides; Soot (including $\mathrm{BC}$ ).

toxic among them - benz (a) pyrene $\mathrm{C}_{20} \mathrm{H}_{12}$, which is an indicator of the presence of other polycyclic arenes in the exhaust gas.

Particulate matter emissions are mainly affected by the presence of a sufficient mass of oxygen in the formation and combustion of the mixture. In the range close to full load, particulate emissions increase [1].

\section{Discussion}

The researches in the field of completeness of combustion of diesel fuel are promising, as they can help increase the efficiency of internal combustion engines, which in turn will reduce the negative impact on the environment and human health. It is also necessary to search for the most suitable fuel engine for operation in terms of its quality composition.

\section{Conclusion}

For combustion with the formation of the least amount of soot, it is necessary to use a long ignition delay.

In this case, too much fuel can be prepared, which can lead to pressure surges. As a result, more nitrogen oxides $\mathrm{NO}_{x}$ can form in the exhaust gases. It should also be noted that fuel combustion depends on its quality composition and, accordingly, its ability to efficiently atomize, mix and further ignite it. When the percentage of heavy fractions in 
the fuel composition is high, the likelihood of incomplete combustion of hydrocarbons in a diesel engine is greater.

The data from preliminary studies will be used to further study the dependence of the design features of internal combustion engines and the composition of exhaust gases.

\section{Funding}

This work was supported by the Federal State Educational Institution of Higher Education Murmansk State Technical University.

\section{Acknowledgement}

The authors would like to thank their colleague for their contribution and support to the research. They are also thankful to all the reviewers who gave their valuable inputs to the manuscript and helped in completing the paper.

\section{Conflict of Interest}

The authors have no conflict of interest to declare.

\section{References}

[1] Dyachenko, N H. (1974). The theory of the internal combustion engine. Leningrad: Mechanical engineering.

[2] Evans, M., Kholod, N., Malyshev, S. Yu. V., Gusev, E., Barinov, A., Tretyakova, S. (2015). Black carbon emissions from Russian diesel sources: case study of Murmansk. Atmospheric Chemistry and Physics, vol. 15, № 14, p. 8349-8359.

[3] Kholod, N., Evans, M., Gusev, E., Malyshev, S. Yu. V., Barinov, A., Tretyakova, S. (2016). A methodology for calculating transport emissions in cities with limited traffic data: Case study of diesel particulates and black carbon emissions in Murmansk. Science of The Total Environment, p 305--313.

[4] Kittelson, D.B., Watts, W.F, Johnso, J. P. (2006). On-road and laboratory evaluation of combustion aerosols---Part1: Summary of diesel engine results. Journal of Aerosol Science, vol. 37, issue 8, pp. 913-930. 
[5] Rodriguez-Navarro, C., Sebastian, E. (1996). Role of particulate matter from vehicle exhaust on porous building stones (limestone) sulfation. Science of The Total Environment, vol. 187, Issue 2, pp. 79-91.

[6] RÖnkkÖ, T., Virtanen, A., Kannosto, J., Keskinen, J., Lappi, M., Pirjola, L. (2007). Nucleation Mode Particles with a Nonvolatile Core in the Exhaust of a Heavy Duty Diesel Vehicle. Environ. Sci. Technol, vol. 41(18), pp. 6384-6389.

[7] Valavanidis, A. (2008). Airborne Particulate Matter and Human Health: Toxicological Assessment and Importance of Size and Composition of Particles for Oxidative Damage and Carcinogenic Mechanisms. Journal of Environmental Science and Health, Part C Environmental Carcinogenesis and Ecotoxicology Reviews, vol. 26, issue 4, pp.339-362.

[8] Argacha, J. F., Bourdrel, T., van de Borne, P. (2018). Ecology of the cardiovascular system: A focus on air-related environmental factors. Trends in Cardiovascular Medicine, vol. 28, Issue 2, p.p.112-126.

[9] Arena, F., Ticali, D. (2018). The development of autonomous driving vehicles in tomorrow's smart cities mobility. AIP Conference Proceedings, vol. 2040, Issue 1 , American Institute of Physics Inc., USA.

[10] Yan, F., Winijkul, E., Jung, S., Bond, T.C., Streets, D.G. (2011). Global emission projections of particulate matter (PM): I. Exhaust emissions from on-road vehicles. Atmos. Environ, vol. 45, pp. 4830--4844.

[11] Langat, K. L. (2010). Performance and Emission Characteristics of Spark Ignition Engines Based on Engine Operating Parameters, unpublished PhD thesis, Egerton University.

[12] Rönkkö, T; Timonen, H. (2019). Overview of Sources and Characteristics of Nanoparticles in Urban Traffic-Influenced Areas. Journal: Journal of Alzheimer's Disease, vol. Pre-press, no. Pre-press, pp. 1-14.

[13] Ogur, E. O., Kariuki, S.M. (2014). Effect of Car Emissions on Human Health and the Environment. International Journal of Applied Engineering Research, no. 21 pp. 1112111128.

[14] Razvitie transportnoi infrastruktury v Rossii v 2015 g. (2015). Moscow, National rating agency.

[15] Jonnaert, E. (2017). The automobile industry pocket guide. Brussels: European Automobile Manufacturers Association. 